\title{
Strongyloidiasis: Risk and Healthcare Access for Latin American Immigrants Living in the United States
}

\author{
Graciela Ostera $^{1} \cdot$ James Blum $^{1}$ \\ Published online: 3 February 2016 \\ (C) The Author(s) 2016. This article is published with open access at Springerlink.com
}

\begin{abstract}
This commentary discusses our current understanding about Strongyloides stercoralis prevalence rates in the United States (USA) in the context of healthcare delivery to immigrants from Latin America. A literature search reveals that while prevalence rates in Latin American countries are not well documented, the rates in Latin American immigrants living in the USA are even less well known. This limited understanding compounds the health challenge facing immigrants who already have limited access to the healthcare system. To better address this problem, we suggest improved parasitological screening plus additional funding for free clinics.
\end{abstract}

Keywords Strongyloides stercoralis · Prevalence · Immigrants $\cdot$ Healthcare access

\section{Introduction}

Large migratory waves have always shaped the ethnic composition of the United States (USA). In particular, the past 50 years have been characterized by a steady stream of immigrants from Latin America, making individuals of Hispanic/ Latino origin the largest group of foreign-born in this country.

Institutions which provide healthcare services to immigrant groups need to be aware of the possible endemic conditions

Graciela Ostera

osterag@georgetown.edu

James Blum

jblum272@gmail.com

1 Department of Microbiology and Immunology, Georgetown University Medical Center, Washington, DC 20007, USA present in this population in order to provide adequate care and anticipate future needs.

There are almost 12 million unauthorized migrants currently living in the USA, of which 8.1 million (71\%) originated in Mexico and Central American countries, where gastrointestinal parasites are endemic due to inadequate sanitary conditions [1]. Unauthorized immigrants bypass the mandated medical examination that US immigration authorities impose on those who petition their residency. While all other immigrants who petition for legal residence in the USA must undergo some form of medical examination, only refugees receive treatment for presumptive strongyloidiasis, schistosomiasis, and soil-transmitted helminths (STH) [2].

This is of particular concern when we consider Strongyloides stercoralis, a nematode generally classified separately from the group of STH composed by Ascaris lumbricoides, Trichuris trichiura, Necator americanus, and Ancylostoma duodenale [3].

S. stercoralis causes a gastrointestinal infection that has several distinctive features. First, $S$. stercoralis can cause a lifelong infection due to its capability to re-infect its human host. This infection can become life-threatening under some conditions. Second, laboratory tests to diagnose most STH are not sensitive enough to reliably detect $S$. stercoralis due to its low larval content in stool. Third, $S$. stercoralis prevalence in Latin American countries is incomplete. Finally, the antihelminthic drugs most frequently used in STH deworming campaigns in the region (albendazole and mebendazole) are highly effective against STHs, but they are not the preferred drugs for S. stercoralis.

In this commentary, we will focus on $S$. stercoralis prevalence in Central America, particularly in Mexico, Guatemala, El Salvador, and Honduras, because these are the top four Latin American countries of origin for unauthorized immigrants to the USA [1]. 
We will also analyze prevalence data from Latin American immigrants currently living in the USA. Though this article is not an exhaustive review on this topic, our intention is to emphasize what we know about $S$. stercoralis prevalence rates to the medical community providing health services to immigrant groups. To that end, we also discuss the medical capabilities of two large charity healthcare organizations serving predominantly Hispanic/Latino immigrants in the Washington, DC metropolitan area.

\section{Strongyloidiasis Prevalence in the Americas}

We consulted epidemiological information made available by the Pan-American Health Organization (PAHO). PAHO plays a significant role in the systematic surveillance, design, and execution of deworming campaigns targeting STHs in the region. However, these surveillance programs have not included, so far, an assessment of S. stercoralis epidemiology. According to PAHO executive staff, efforts are currently underway to design and implement a much-needed systematic and standardized surveillance of $S$. stercoralis prevalence. In their literature review from July 2013, Schär and colleagues summarized the results of independent, Latin American-based studies investigating $S$. stercoralis prevalence rates. The authors note significant variations in the available data based on the type of study they found (e.g., community-based vs. hospital-based studies) as well as on the different sensitivity (low, medium, or high) of the diagnostic methods [3-5].

As an example, some $S$. stercoralis prevalence rates for selected countries are Mexico (1.6 and $5.7 \%$ ), Guatemala (unavailable and $2 \%$ ), and Honduras (3.2 and 29.8\%) for community-based and hospital-based studies, respectively [3]. Those values include diagnostic methods with different sensitivities. No data was available for El Salvador.

Collectively, this prevalence data show how difficult it would be to estimate $S$. stercoralis health risk in this sub-group of Latin American countries with the information that is currently available and underscores the need for a systematic surveillance approach.

Looking at the S. stercoralis data currently available on foreign-born individuals living in the USA, the Centers for Disease Control and Prevention (CDC) report a prevalence range between 0 and $46.1 \%$ [6]. This wide range comprises data obtained from different international immigrant groups. Values on the upper end of this range correspond to studies investigating refugee groups from Africa and Asia (e.g., $46 \%$ prevalence in a group of Sudanese refugees) [7].

We searched for $S$. stercoralis prevalence rates, limiting the query to studies performed in the USA between 1990 and 2015 on subjects born in Latin America who are not immunocompromised, and found only four studies. However, only two of these studies were performed in healthy individuals while the other two investigated $S$. stercoralis in patients with a medical condition [8-11] (Table 1).

Clearly, prevalence values ranging from 4.6 to $10.5 \%$ are on the lower end of the ones reported by the CDC. Recent $S$. stercoralis prevalence data obtained by our group also falls within this range (unpublished data). It is not known whether patients included in these studies were subjected to presumptive deworming treatments in their country of origin or in the USA that could have reduced the proportion of positive cases detected. Future studies controlling this variable are needed.

From this data, we conclude that while it may not be possible to accurately estimate the $S$. stercoralis health risk in Latin American immigrants, limited surveillance studies performed in the USA seem to indicate prevalence values between 5.0 and $10.0 \%$. Although actual S. stercoralis prevalence needs to be refined, this information can still be useful to medical service providers.

\section{Healthcare Options for the New and Undocumented Immigrant}

In the USA, recent documented and undocumented immigrants have limited access to health care. Under the Affordable Care Act (ACA), immigrants who are lawfully present in the USA who do not have employer-provided health insurance are able to purchase private health insurance through the government's marketplaces only after 5 years of residence in the country [12].

The vast majority of undocumented immigrants or those with a legal immigration status but who don't have health insurance are forced to seek care through emergency rooms, federally qualified health centers (FQHC), and charitysupported free clinics, with the exception of a small number of states that use their own funds to provide Medicaid and Children's Health Insurance Program (CHIP) coverage.

Table 1 S. stercoralis prevalence studies performed in the USA on Latin American immigrants, 1990-2015

\begin{tabular}{llll}
\hline Citation & $\begin{array}{l}\text { Diagnostic } \\
\text { method }\end{array}$ & $\begin{array}{l}\text { Prevalence } \\
(\%)\end{array}$ & $\begin{array}{l}\text { Immigrant's country } \\
\text { of origin }\end{array}$ \\
\hline $\begin{array}{c}\text { Rapoport } \\
\text { et al. [10] }\end{array}$ & ELISA & 5.8 & Brazil \\
$\begin{array}{c}\text { Fitzpatrick } \\
\text { et al. [8] }\end{array}$ & ELISA & $4.6^{\mathrm{a}}$ & Mexico, Ecuador, Peru \\
$\begin{array}{c}\text { Wehner } \\
\text { et al. [9] }\end{array}$ & ELISA & $10.5^{\mathrm{b}}$ & $\begin{array}{c}\text { Mexico, Central and } \\
\text { South America }\end{array}$ \\
$\begin{array}{c}\text { Ciesielski } \\
\text { et al. [11] }\end{array}$ & Stool sample & 6.1 & $\begin{array}{c}\text { Mexico, Central } \\
\text { America, and Haiti }\end{array}$ \\
\hline
\end{tabular}

${ }^{a}$ Kidney transplant candidates

${ }^{\mathrm{b}}$ Patients with asthma 
We interviewed administrative officers at two large primary care organizations that provide medical services in the Washington, DC metropolitan area to a population that is predominantly uninsured or below the federal poverty line. Combined, these two organizations provide over 70,000 patient visits per year. Eighty percent of these services are delivered to uninsured individuals of Hispanic origin.

In 2014, the smaller of these two organizations provided medical care worth 4.7 million US dollars to individuals who were unable to pay for medical services.

Maria Gomez, the president and CEO of Mary's Center, a FQHC in Washington, DC stressed that these clinics deliver much-needed primary care in response to top medical concerns in the adult and pediatric populations they serve. Services focus on frequently observed conditions such as obesity, hypertension, diabetes, prenatal care, and several common pediatric concerns. However, these two healthcare organizations stated that they are not able to offer routine parasitological screening to their patients due to the high cost of laboratory tests. One clinic admitted that specific parasitological training would be beneficial to increase awareness in their team of primary care practitioners (doctors and nurses). Unfortunately, S. stercoralis infection can have fairly unspecific symptoms and practitioners may not consider this presumptive diagnosis initially.

\section{Conclusion}

Our current understanding of $S$. stercoralis infection prevalence rates in Latin American immigrants in the USA is affected by the following factors:

1. Lack of standardized prevalence data available from countries in the Latin American region

2. Very limited number of studies documenting $S$. stercoralis prevalence rates in Latin American immigrants living in the USA

3. Limited healthcare accessibility for immigrants: generally limited to primary care, which may be affected by cost restrictions on diagnostic services for gastrointestinal parasitic infections

Given the current global landscape, it is critical that we are prepared to identify and treat patients with neglected parasitic infections (NPI) coming to the USA from different parts of the world. We should consider the systematic screening of parasitic diseases by immigration authorities at borders and community-based screening in areas with high immigrant density. For clinics that are already providing health care to vulnerable populations, additional funding is needed to cope with an increased number of patients and complexity of services.

\section{Compliance with Ethical Standards}

Conflict of Interest Graciela Ostera and James Blum declare that they have no conflict of interest.

Human and Animal Rights and Informed Consent This article does not contain any studies with human or animal subjects performed by any of the authors.

Open Access This article is distributed under the terms of the Creative Commons Attribution 4.0 International License (http:// creativecommons.org/licenses/by/4.0/), which permits unrestricted use, distribution, and reproduction in any medium, provided you give appropriate credit to the original author(s) and the source, provide a link to the Creative Commons license, and indicate if changes were made.

\section{References}

1. Migration Policy Institute's frequently requested statistics on immigrants and immigration in the United States. Washington, DC February 2015. Accessed 12 Jan 2016. http://www.migrationpolicy. org/article/frequently-requested-statistics-immigrants-andimmigration-united-states\#Unauthorized\%20Immigration.

2. Centers for Disease Control and Prevention. Presumptive treatment and screening for strongyloidiasis, schistosomiasis and infections caused by soil-transmitted helminths for refugees. Accessed 12 Jan 2016. http://www.cdc.gov/immigrantrefugeehealth/guidelines/ domestic/intestinal-parasites-domestic.html.

3. Schär F, Trostdorf U, Giardina F, Khieu V, Muth S, Mart H, et al. Strongyloides stercoralis: global distribution and risk factors. PLoS Negl Trop Dis. 2013;7(7), e2288.

4. Koga K, Kasuya S, Khamboonruang C, Sukhavat K, Ieda M, Takatsuka N, et al. A modified agar plate method for detection of Strongyloides stercoralis. Am J Trop Med Hyg. 1991;45(4):518-21.

5. Yori PP, Kosek M, Gilman RH, Cordova J, Bern C, Chavez CB, et al. Seroepidemiology of strongyloidiasis in the Peruvian Amazon. Am J Trop Med Hyg. 2006;74:97-102.

6. Centers for Disease Control and Prevention. Strongyloides epidemiology \& risk factors. Accessed 12 Jan 2016. http://www.cdc.gov/ parasites/strongyloides/epi.html.

7. Posey DL, Blackburn BG, Weinberg M, Flagg EW, Ortega L, Wilson M, et al. High prevalence and presumptive treatment of schistosomiasis and strongyloidiasis among African refugees. Clin Infect Dis. 2007;45(10):1310-5.

8. Fitzpatrick MA, Caicedo JC, Stosor V, Ison MG. Expanded infectious diseases screening program for Hispanic transplant candidates. Transpl Infect Dis. 2010;12(4):336-41.

9. Wehner JH, Kirsch CM, Kagawa FT, Jensen WA, Campagna AC, Wilson M. The prevalence and response to therapy of Strongyloides stercoralis in patients with asthma from endemic areas. Chest. 1994;106(3):762-6.

10. Rapoport AB, McCormick D and Cohen PA. Screening for Schistosoma mansoni and Strongyloides stercoralis infection among Brazilian immigrants in the United States. Open Forum Infect Dis. 2015;2(1):ofv003. doi:10.1093/ofid/ofv003.

11. Ciesielski SD, Seed JR, Ortiz JC and Metts J. Intestinal parasites among North Carolina migrant farmworkers. Am J Public Health. 1992;9:1258-62.

12. Cacari-Stone L, Steimel L, Vasquez-Guzman E. The potential conflict between policy and ethics in caring for undocumented immigrants at academic health centers. Acad Med. 2014;89:536-9. 